\title{
Mobile Total Conversation - Communication for All, Everywhere
}

\author{
Erik Zetterström \\ Omnitor $\mathrm{AB}$, \\ Hammarby allé 93, 12063 Stockholm, Sweden \\ erik.zetterstromaomnitor.se
}

\begin{abstract}
This paper describes a demonstration of an open source Total Conversation client for the Android mobile phone platform. It also explains the rationale for Total Conversation and gives a brief overview of the open standards on which Total Conversation is based.
\end{abstract}

Keywords: Total Conversation, mobile, Deaf, Sign language, Video conference, Android, disabilities.

\section{Introduction}

Mobile phones have been a natural part of our life for, at least, the last 15 years. Mobile phones allow everyone the convenience to communicate with anyone anywhere, well not quite everyone after all. For those whose native language is a sign language this has not been the case. These individuals have been confined to using SMS or in some cases 3G video telephony. Not having equal access to telephony is clearly in violation of the United Nations Convention on the Rights of People with Disabilities [1], still the convention has been ratified by 99 countries [2]. This demonstration intends to showcase how mobile Total Conversation enables equal access to mobile telephony.

\section{Total Conversation}

The purpose of Total Conversation is to enable communication for all. Mobile phones and modern telecommunication networks have advanced to the point where it is now possible to deploy Total Conversation on most high end phones. The simultaneous use of audio, video and real-time text allows all users to find a suitable method for communication.

Video can be used for sign language or lip-reading for those who are deaf, hard of hearing, deaf-blind or late deafened.

Audio can be used for voice conversation according to the user's capabilities.

Real-time text can be used by everyone to convey information that is tedious to convey in other media. It can also be used to support other media in the call for example; through a captioned telephony service or in some cases to type a word instead of speaking it for someone with a speech impairment. For deaf blind users it could be used to receive text while the response may be sent in sign language. 
Total Conversation is based on open standards and is defined in [3]. As in most open IP telephony systems today the Session Initiation Protocol (SIP) [4] and RTP [5] is used. H.263 [6] and H.264 [7] should be supported for video. H.263 is widely implemented and the newer H.264 offers better video quality with less bandwidth. G.711 [8] is recommended for audio since it is widely supported and offers good quality. Real-time text should be implemented by T.140 [9]. It provides character by character transmission, giving the user a sense of a real conversation.

For good communication in sign language the video resolution should not be below QCIF $(176 \times 144)$ and 20 frames per second (fps) is recommended [10].

\section{Demonstration Description}

The demonstration will showcase the benefits of Total Conversation being added to the open source mobile Total Conversation client linphone [11] running on Android mobile phones. Calls to and from this client to other proprietary and open source clients Total Conversation will demonstrate the importance of open standards for interoperability.

During the demonstration lessons learned will be presented, for example regarding $\mathrm{CPU}$ and network requirements.

\section{References}

1. Convention on the Rights of Persons with Disabilities, http: / / www . un. org/disabilities/default.asp?id=150

2. Convention on the Rights of Persons with Disabilities - Convention and Optional Protocol Signatures and Ratifications,

http: / / www . un .org/disabilities/ countries. asp? id=166

3. ITU-T F.703 Telecommunications accessibility guidelines for older persons and persons with disabilities, http: / /www. itu.int/rec/T-REC-F. 703

4. IETF RFC3261 SIP: Session Initiation Protocol, http: / /www. ietf.org/rfc/rfc3261.txt

5. IETF RFC3550 RTP: A Transport Protocol for Real-Time Applications, http: / / www. ietf.org/rfc/rfc3550.txt

6. ITU-T H.263 Video coding for low bit rate communication, http: / / www.itu.int/rec/T-REC-H.263/

7. ITU-T H.264 Advanced video coding for generic audiovisual services, http: / /www.itu.int/rec/T-REC-H.264/

8. ITU-T G.711 Pulse code modulation (PCM) of voice frequencies, http: / / www.itu.int/rec/T-REC-G.711/

9. ITU-T T.140 Protocol for multimedia application text conversation, http: / /www.itu.int/rec/T-REC-T.140/

10. ETSI EG 202670 Human Factors (HF) User Experience Guidelines for real-time communication services expressed in Quality of Service terms

11. linphone - an open source video SIP phone for desktop \& mobile, http: / /www. linphone.org / 